\title{
Is Self neglect associated with the Emotional and financial abuse in community-dueling?
}

\author{
${ }^{1}$ Homa Mardan, ${ }^{2}$ Prof Dr Gisa Jaehnichen, ${ }^{3}$ Prof Dr Tengku Aizan Hamid \\ ${ }^{1}$ Institute of Gerontology, 43400 UPM, Serdang, Selangor, Malaysia \\ ${ }^{2}$ Faculty of Human Ecology, 43400 UPM, Serdang, Selangor, Malaysia \\ ${ }^{3}$ Institute of Gerontology, 43400 UPM, Serdang, Selangor, Malaysia
}

\begin{abstract}
With an increasing aged population, health issues in elderly, especially in women, are raised. This study discusses findings about the association between emotional and financial abuse and elder self-neglect (ESN) as a hidden concern in a population of community-dwelling elder adults. The study is based on a prior cross-sectional survey on elderly abuse in Malaysia under sponsorship of the Ministry of Science. Participants of the project study were older individuals $(N=480)$ reported to the Gerontology Department for suspected maltreatment that was conducted from January to May 2008 with the face to face interview method using enumerator-administered questionnaires. The primary outcome of the project on emotional and financial abuse supported by the Ministry of Science, Technology and Innovation (MOSTI), that assessed using emotional (5 items) and financial abuse (4 items), and self neglect (7 items) test. Correlation regression was utilized to assess this association. After consideration of confounding, higher emotional and financial abuse, respectively were associated with self neglect in elder persons (coefficient $=95 \%, p=.001$ ). Other Socio-demographic risk factors were also high correlated with ESN behavior. Elderly abuse and self-neglect is a common issue across all countries and as the significant threat to the health of elderly. However, a correlation between different kinds of abuses shows that emotional and financial abuses are more likely to experience self neglect in later life. Other Socio-demographic risk factors have to be discussed.
\end{abstract}

Key words: Emotional abuse; financial abuse; self neglect; cross-sectional study; health elderly.

\section{Introduction}

As rising aging population in worldwide, the severity of elder abuse especially self neglect is increased that can effect on health public, unsafe and unhealthy conditions for later life. Elder self neglect (ESN) is a common global public health issue in all groups with a high cost for society and individuals and their family. Evidence shows that there are approximately 1.2 million cases of ESN in United States annually (National Center on Elder Abuse, 1998). Based on ESN definition by this center, self neglect is considered as behavior of elderly that threatens their own health and safety. Most existing information about self neglect is related to reports from social service agencies (Pavlou and Lachs, 2006) that show the prevalence of ESN is increasing. Based on National Center on Elder Abuse (2006), the categories of abuse in older persons aged 60:

- Self-neglect was the most common category of investigated reports $(49,809$ reports or 26.7\%), followed by caregiver neglect (23.7\%), and financial exploitation (20.8\%) (195 States).

- Self-neglect was the most common category of substantiated reports (26,752 reports or $37.2 \%)$, followed by caregiver neglect (20.4\%), and financial exploitation (14.7\%) (195 States).

In Malaysia, the population of aging also is increased (Figure 1) from average 17 million (y-axis) in January 2002 to approximately 29 million in January 2012 (Malaysian population online) because of the raising life expectancy. With increase population, the incidence of elder abuse may be raised.

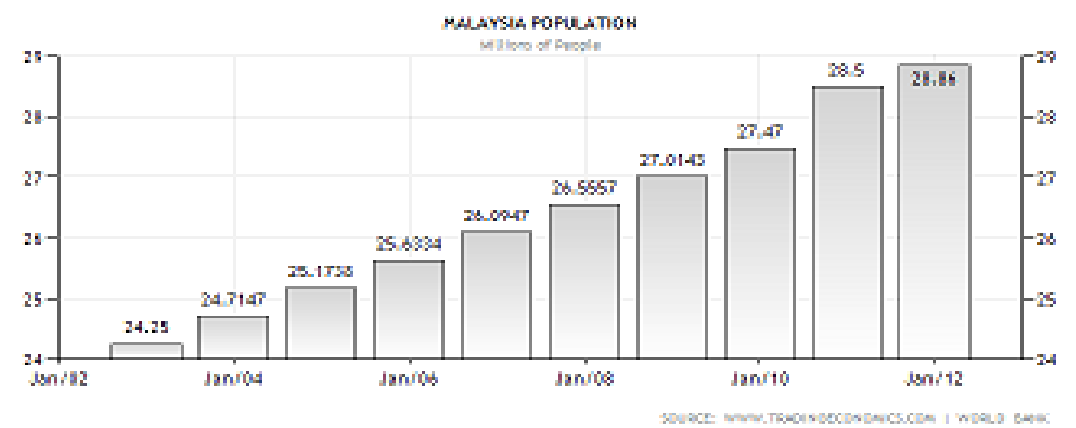

Figure 1: The situation of Malaysian population based on million during a ten years period (2002-2012). 
(Malaysian population online)

Elder abuse and self neglect are common concerned as medical, psychological and social issue across all countries. However, linking between emotional and financial abuse (as the highest level among other abuse) with self neglect in later life is still unclear. Other Socio-demographic risk factors need to be discussed.

Emotional and financial abuses have been associated with demographic factors. Prior study has illustrated a correlation of mistreatment and kinds of abuse: emotional, physical, and financial with family members. The potential abuse and sexual abuse with computer assisted telephone interviewing method among 5777 elder persons 60 years old and above confirms linking between types of abuse (Acierno et al., 2010). In addition, it is found that financial abuse related by family members. The potential neglect and emotional abuse respectively were the most frequent among the rest of abuse types. In the United Kingdom, neglect, financial and psychological abuses respectively are those with the highest frequency and physical and sexual abuses are the lowest. Additionally, women were significantly related to that experience compared with men in difference types of abuse. Moreover, mistreatment varied and abuse with health status and socioeconomic position (Santos et al., 2011); Biggs et al., 2009).

An overview about the experience of abuse in older adults in Malaysia by Hamid et al., 2009), has been found that the most prevalence of abuse related to emotional and financial abuse (Figure 2) although, based on information of this study, the majority of respondents did not have abuse (74\%). However, after a few years later in same population in Malaysia, author's report illustrated having experienced at least one kind of abuse during past 50 years among elder persons in basic study (Hamid et al., 2011).
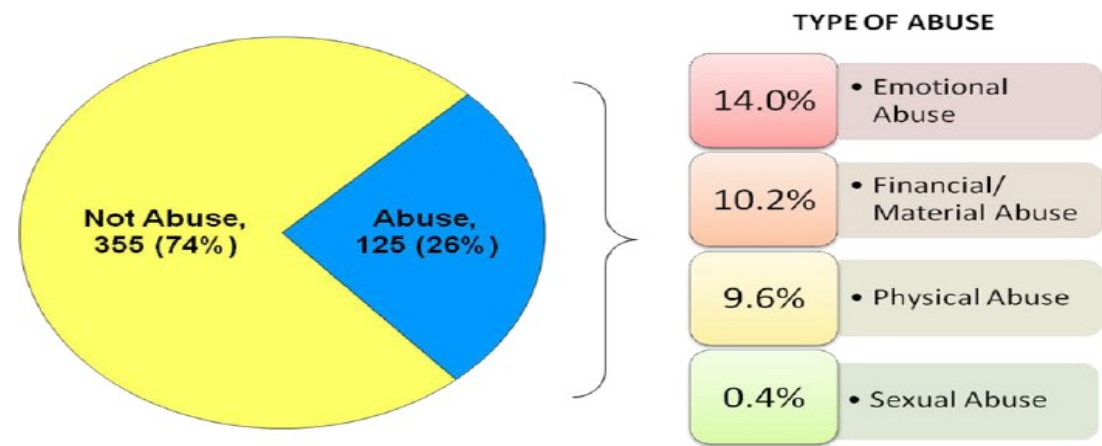

Figure 2: Experience of abuse among the respondents $(\mathrm{N}=480)$, Source: Hamid et al., 2009

Additionally, among Socio-demographic respondents' characteristics who experience abuse, the highest prevalent abuse belonged to young elderly (60-70), being female, Malay, married, being provided with formal education, unemployed and being owners. In recent study, Abdel Rahman, and El Gaffary (2012), revealed that physical, emotional and financial abuse, after neglect were the most frequent with the highest level of abuse among older persons that especially neglect with increasing age is raised, as well. Teaster, (2006) revealed that self neglect has the highest frequency (39\%) among other types of abuse whiles sexual and emotional abuse were the lowest, respectively (Figure 3). However, the linking between emotional and financial abuse with self neglect is still unclear and study in this area is really limited.

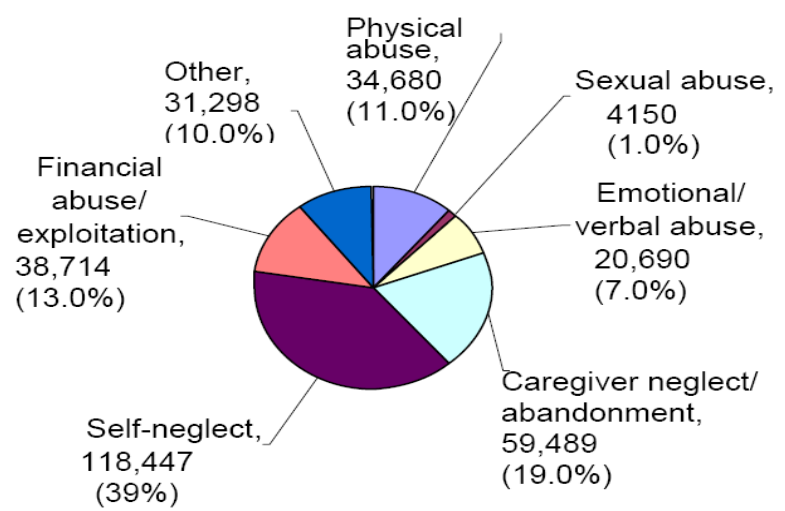

Figure3: The high frequency of ESN (39\%) compared with other abuses (Teaster, (2006) 


\section{Self neglect and risk factors:}

Based on evidence and results of recent study, self neglect is as a hidden, multidimensional complex behavior and global issue (Alexa et al., 2012). It is considered as an important medical issue, or diagnoses syndrome with limitation of definition unique instrument, cultural-dependence and lack of theory (Kelly et al., 2008). Despite of these deficiencies, the prevalence of ESN is high (Garre-Olmo et al., 2009); Lowenstein, 2009). So, regarding to Lowenstein, 2009 conclusion, developing study and data base in international, national and regional level and policy, intervention, and educational programs are suggested. Because of these reason above, identification, prevention and treatment of ESN will likely difficultly.Furthermore, greater self-neglect severity associated with lower levels of physical function and physical performance (Dong et al., 2009a) and mortality (Jasmer, 2009). Acierno et al., 2010) mentioned that emotional abuse as the highest level compared with other abuse, associated with low social support.

On the other side, some experts (Band-Winterstein et al., 2012) believe that self-neglect should be considered as a life course story instead of geriatric syndrome (Pavlou and Lachs, 2006). However, opponents emphasize on diagnosis syndrome of self neglect that associated to dementia, neuropsychological and social risk factors such as living alone (Tierney et al., 2007; Dick, 2006).

It seems that diversity of these different considerations of definition and risk factors associated to ESN is due to lack of adequate attention on types of self neglect (intentional and unintentional). Life course study, life style may associate to intentional type of self neglect as a primary and diagnoses because of physical and mental disorder can relate to the unintentional and secondary type of self neglect that needs to treatment. Another reason to need to understand this phenomenon is because of different definition of ESN due to different meaning of its dimensions in diverse of culture, (i.e. different meaning of dirty among different people). Thus, it is essential to investigate ESN through comprehensive systematic study on the population (Ernst and Smith, 2011). Thinking of ways to control this phenomenon after better understanding through Bio-Psycho Social perspective (Mardan and Hamid, 2012) is vital. Additionally, more study about risk factors of intentional and unintentional for treatment, presentation and prediction need to reduce this complex multidimensional behavior base on social environment, capacity and daily activities (Ernst and Smith, 2011) to help people who are in the earlier of stage ESN.

In this cross-sectional study the association between Emotional and financial abuse and severity of self neglect is examined within the population based cohort. It is hypothesized that higher emotional and financial abuse are associated with higher severity of self neglect.

\section{Method}

Setting: The Ministry of Science, Technology and Innovation (MOSTI), is a study about experience of maltreatment for abuse's experience in Malaysian population that began in 2008 with two groups of participation from 20-50 and elderly from 60 years and older of four zones of Malaysia, contain of Perak, Melaka, Kelantan and Selangor in peninsular Malaysia which is reported on published previously (Hamid et al., 2009). Of the 1,334 total respondents, 480 elder residents living in the community identifiable (one third) from 1,079 respondents were successfully interviewed by enumerators of ministry.

In this cross- sectional study, data collected from January to May 2008 within the face to face interview method and utilizing enumerator-administered questionnaires about experience of any abuse during 50years ago. The experience of elder abuse was measured by 19 items in instrument developed by study team by financial abuse (4 items), emotional (5 items), physical (4 items), sexual abuse (6 items) and self neglect (7 items) with categories by yes, no, and not applicable.

In current study, for examination of whether linking between emotional and financial abuse associated with self neglect, utilized descriptive statistical, comparison means and correlation regression models for Sociodemographic age, gender, race, education and income to describe, predict and explain this link for analytic approach. Also, model repeated controlling for Socio-demographic. Analyses were carried out utilizing SPSS version 21 .

\section{Results}

The Socio-demographic of aging shows that the mean age of the 480 elder participants in this study, was 69 years old with $56 \%$ of female population. In Malaysian population, $75.02 \%$ of older adults who experience abuse or neglect were young old (60-69), with 56\% married, $63.02 \%$ formal education, and $68 \%$ owner. Furthermore, slightly $89 \%(88.88 \%)$ of them with more percentiles of Malay people $(71.2 \%)$ were unemployed. Financial and emotional abuses were the highest level in compared with of physical and sexual abuse that these results have confirmed by other previous research (Acierno et al., 2010, Abdel Rahman, and El Gaffary, 2012). Although, some researcher revealed the high level of emotional and financial abuse especially from children or spouse and family members, high level of self neglect is the significant issue especially in 
elderly that may ignored among the previous research. Current research investigated that this hidden problem had the high prevalence among other abuse (table 2 ) that can lead to mortality.

Table 1: Four states with percentage of the total participation $(\mathrm{N}=480)$

\begin{tabular}{cccccc}
\hline & & Frequency & Percent & Valid Percent & Cumulative Percent \\
Valid & Selangor & 117 & 24.4 & 24.4 & 24.4 \\
& Melaka & 116 & 24.2 & 24.2 & 48.5 \\
& Perak & 105 & 21.9 & 21.9 & 70.4 \\
& Kelantan & 142 & 29.6 & 29.6 & 100.0 \\
Total & $\mathbf{4 8 0}$ & 100.0 & 100.0 & \\
\hline
\end{tabular}

Table 1 shows population area with total 480 older persons in four states of Pennsylvania, Malaysia. The Kelantan state with approximately 30 percent had the highest population of aging among other states selected in this study. Other states have the same situation in terms of aging population.

Table 2: comparison means of self neglect, Emotional and financial abuse

\begin{tabular}{|l|r|r|r|}
\hline \multicolumn{4}{|c|}{ Descriptive Statistics } \\
\hline & Mean & Std. Deviation & \multicolumn{1}{c|}{ N } \\
\hline Self neglect & $\mathbf{1 3 . 0 6 2 5}$ & 1.36778 & 480 \\
\hline Emotional abuse & 9.0042 & 1.10417 & 480 \\
\hline Financial abuse & 9.8125 & .73551 & 480 \\
\hline
\end{tabular}

As it is seen from information of the table 2, self neglects' mean is the highest amount (13.06 \%) compared with emotional $(9.00 \%)$ and financial abuse $(9.81 \%)$. Before that, Teaster (2006) also has found the high frequency of self neglect (39\%) compared with other abuses. Furthermore, with Pearson Correlation analysis, there is significant correlation between self neglect and financial \& emotional abuse in level of 0.01 , and 0.05 , respectively. Also, the situation of poverty is shown in pie chart below. It is clear that the majority of elderly who experience abuse have low income and only $13.6 \%$ of them do not have any financial problem.

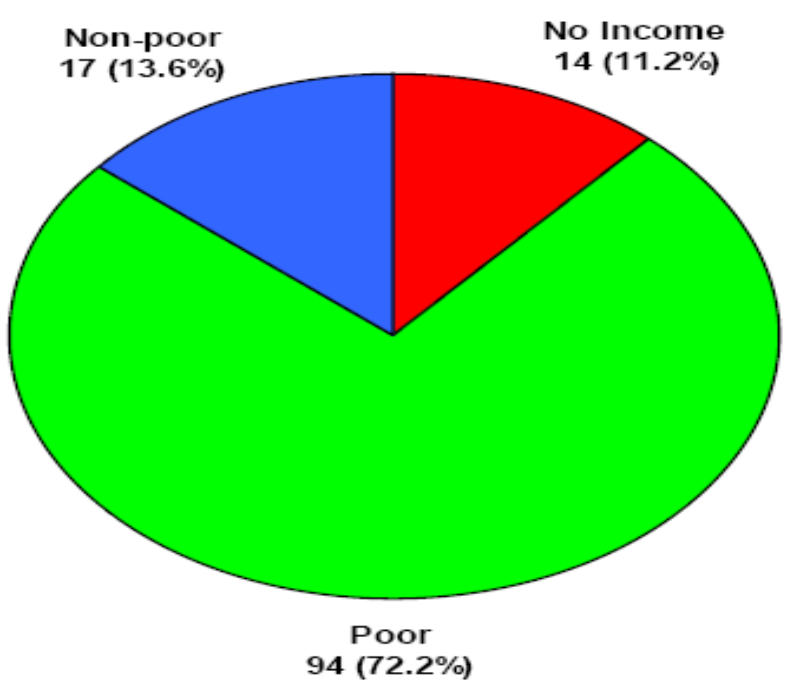

Figure 4: Monthly income elderly with experience of abuse

It is cleared from information of figure 4 that the majority of elderly who experience abuse have poverty (72.2) and no any income (11.2\%). Indeed, poverty can lead to commit the abuse and self neglect, as well. So, it should be considered as the significant Socio-demographic factor. Additionally, based on the results of table 3, the socio-demographic characteristics of elderly who experience abuse, it is surprised that married people had the higher level of abuse compared with unmarried. Also, it is clear that unemployed (88.8\%) had high level of abuse (table 4) because of strong correlation between poverty and abuse (figure 4). It is obvious from the table 3 that female and young old 60-74 and Malay married experience abuse is more than the other groups. Also surprisingly people who have formal education or owner in house had experience of abuse at least two times more than others with no ownership and no formal education. However, it is not apparent why owner had more experience of abuse in comparison with others. More research is needed to understand better why people with high education level and married especially being women in Malaysia had experience of abuses more than the others. Also, In Malaysia same other countries, the correlation between kinds of abuse and self 
neglect is high (table 4) that means having experience of abuse even in the past can increase self neglect behavior in elderly. This is the key point that needs to pay attention on by everybody whose concern about elder issues.

Table 3 Socio-demographic characteristics of the respondents ever experienced abuse

\begin{tabular}{|c|c|c|}
\hline Variables & $N$ & $(\%)$ \\
\hline \multicolumn{3}{|c|}{$[\mathrm{M}=69.42, \mathrm{SD}=8.311]$} \\
\hline Young - old $(60-74)$ & 94 & 75.2 \\
\hline \multicolumn{3}{|l|}{$[\mathrm{M}=65.51, \mathrm{SD}=4.517]$} \\
\hline Old - old $\quad(75-84)$ & 23 & 18.4 \\
\hline \multicolumn{3}{|l|}{$[\mathrm{M}=78.61, \mathrm{SD}=2.824]$} \\
\hline Oldest - old $\quad(>85)$ & 8 & 6.4 \\
\hline \multicolumn{3}{|l|}{$[\mathrm{M}=88.88, \mathrm{SD}=3.482]$} \\
\hline Sex: Female & 70 & 56.0 \\
\hline Male & 55 & 44.0 \\
\hline Ethnicity: Malays & 89 & 71.2 \\
\hline Non-malays & 36 & 28.8 \\
\hline Marital status: Married & 70 & 56.0 \\
\hline Not married & 55 & 44.0 \\
\hline Number of child(ren) & & \\
\hline Household size & & \\
\hline \multicolumn{3}{|l|}{ Education level } \\
\hline Formal education & 79 & 63.2 \\
\hline No formal education & 46 & 36.8 \\
\hline Employment status: Unemployed & 111 & 88.8 \\
\hline Employed & 14 & 11.2 \\
\hline \multicolumn{3}{|l|}{ House ownership } \\
\hline House ownership: Owner & 85 & 68.0 \\
\hline No ownership & 40 & 32.0 \\
\hline
\end{tabular}

Source: $\underline{\text { Hamid et al., 2011) }}$

Table 4: the significant correlation between IVs (emotional and financial abuse) and DV (self neglect)

\begin{tabular}{|c|c|c|c|c|}
\hline & & Correlati & & \\
\hline & & Self neglect & Emotional abuse & Financial abuse \\
\hline Self neglect & Pearson Correlation & 1 & -.089 & $.138^{* *}$ \\
\hline & Sig. (2-tailed) & & .052 & .002 \\
\hline & $\mathrm{N}$ & 480 & 480 & 480 \\
\hline Emotional abuse & Pearson Correlation & -.089 & 1 & .070 \\
\hline & Sig. (2-tailed) & .052 & & .124 \\
\hline & $\mathrm{N}$ & 480 & 480 & 480 \\
\hline Financial abuse & Pearson Correlation & $.138^{* *}$ & .070 & 1 \\
\hline & Sig. (2-tailed) & .002 & .124 & \\
\hline & $\mathrm{N}$ & 480 & 480 & 480 \\
\hline **. Correlation is & znificant at the 0.01 & ailed). & & \\
\hline
\end{tabular}

\section{Conclusion}

Elder self neglect (ESN) is the important bio-psychosocial issue (Mardan and Hamid, 2012) and health concern with high cost for elderly and society. It may lead to harm and mortality that often considers as a treatment to healthy and safety among older persons. Thus, in order to increase quality of life and healthy older adult, attention to risk factors of ESN is vital. Despite of the fact that self neglect is the highest level among other abuse, (approximately two times more than the others) linking between ESN and other abuse is still unclear. Although a few studies have done about linking between physical, cognitive abuse and self neglect (Dong et al., 2009b). Current study results clarified that there is significant linking between ESN and emotional \& financial abuse, respectively. Furthermore, among Socio-demographic respondents' characteristics of people who experienced abuse with the highest prevalent abuse belonged to young elderly (60-70), being female, Malay, married, being provided with formal education, unemployed, poverty and being owners that can effect on ESN. However, more study is needed to understand why young old married with formal education experience abuse more than the others. So it needs to pay more attention on each planning in advance and making decision in order to enhance aging healthy and safety. Current study's result contributes to the field of ESN showing the link between ESN and other kinds of abuse which was not clear in the past especially in Malaysian community but has some limitation. One of the important limitations of this study due to lack of using unique and international instrument of ESN that may effects on the results of study. Strength instrument is needed to better measure this complex phenomenon. Although linking between emotional, financial abuse with 
self neglect is cleared by this study, but it cannot determine the causality of this link whether self neglect is the reason of the other abuses or vice versa. So, more study is needed to find the cause and effect and the role of moderate and mediate factors of ESN within a comprehensive approach.

\section{Reference}

[1]. Abdel Rahman, T.T. and M.M. El Gaafary, 2012, Elder mistreatment in a rural area in Egypt,Geriatric, Gerontology. Int., 12: 532537

[2]. Acierno, R., M.A. Hernandez, A.B. Amstadter, H.S. Resnick, K. Steve, W. Muzzy and D.G. Kilpatrick,. 2010. Prevalence and correlates of emotional, physical, sexual, neglectful, and financial abuse. Am J Public Health. Feb; 100 (2):292-7. doi: 10.2105/AJPH.2009.163089. Epub 2009 Dec 17. http://www.ncbi.nlm.nih.gov/pubmed/20019303

[3]. Alexa, I.D., A.C. Ilie, A. Morosanu, P. Emmanouil-Stamos and I. Raiha, 2012,. Self neglect in elders: A worldwide issue ignored in Romania.Rom. J. Bioethics, 10: 141-148.

[4]. Santos, A.J., J. Ferreira-Alves and B. Penhale, 2011,. Prevalence of older adults' abuse and neglect in Portugal: An overview. Qual. Ageing Older Adults, 12: 162-173.

[5]. Band-Winterstein, T., I. Doron and S. Naim,. 2012. Elder self neglect: A geriatric syndrome or a life course story? J. Aging Stud., 26: 109-118

[6]. Biggs, S., J. Manthorpe, A. Tinker, M. Doyle and B. Erens, 2009. A Mistreatment of older people in the United Kingdom: Findings from the first national prevalence study. J. Elder Abuse Negl., 21: 1-14.

[7]. Dong, X., C.F. Mendes de Leon and D.A. Evans, 2009a,. Is greater self-neglect severity associated with lower levels of physical function? J. Aging Health, 21: 596-610.

[8]. Dong, X., M. Simon, T. Fulmer, C.F. Mendes de Leon, B. Rajan and D.A. Evans, 2009b.Physical function decline and the risk of elder self-neglect in a community-dwelling population. Gerontologist, 50: 316-326.

[9]. Dick, C., 2006. Self neglect: Diagnosis syndrome and dementia.Kansas Nurse, 81: 12-13.

[10]. Ernst, J.S. and C.A. Smith, 2011,. Adult protective services clients confirmed for self-neglect: Characteristics and service use.J. Elder Abuse Negl., 23: 289-303.

[11]. Garre-Olmo, J., X. Planas-Pujol, S. Lopez-Pousa, D. Juvinya, A. Vila and J. Vilalta-Franch, 2009,. Prevalence and risk factors of suspected elder abuse subtypes in people aged 75 and older. J. Am. Geriatric. Soc., 57: 815-822.

[12]. Hamid, T.A., S. Farra and Y. Nurizan, 2009,. Experience of abuse in old age: An emerging concern. Proceedings of the 10th Islamic Countries Conference on Statistical Sciences, Volume 1, December 20-23, 2009, The Islamic Countries Society of Statistical Sciences, Cairo, Egypt, pp: 17-24.

[13]. Hamid, T.A., Y. Nurizan, A. Samah, M. Mansor and Z. Ahmad, 2011, Perception, awareness and risk factors of elder abuse, Study Summary, Institute of Gerontology, University Putra Malaysia.

[14]. Jasmer, R., 2009. Self-neglect marker for mortality in elderly, JAMA, 302, 517-526.

[15]. Kelly, P.A., C.B. Dyer, V. Pavlik, R. Doody and G. Jogerst, 2008.Exploring self-neglect in older adults: Preliminary findings of the self-neglect severity scale and next steps, J. Am. Geriatric. Soc., 56: S253-S260.

[16]. Lowenstein, A., 2009. Elder abuse and neglect-old phenomenon: New directions for study, legislation and service developments. J. Elder Abuse Neglect, 21: 278-287.

[17]. Mardan, H. and A.T. Hamid, 2012,. Self-neglect in older adults: An overview, Australian journal of Science alert, Acceptance Letter for Article No. 50207-AUJSS-SA, Science Alert for UK \& Europe.

[18]. National Center on Elder Abuse, 1998,. The National Elder abuse incidence study, Report No.: Final.

[19]. National Center on Elder Abuse, 2006,. The 2004 Survey of Adult Protective Services: Abuse of Adults 60 Years of Age and Older, from http://www.ncea.aoa.gov/ncearoot/ Main Site/pdf/021406 60PLUS REPORT.pdf

[20]. Pavlou, M.P. and M.S. Lachs, 2006,. Could self-neglect in older adults be a geriatric syndrome? J. Am. Geriatr. Soc., 54: 831-842.

[21]. Teaster, P.B., 2006,. A response to the abuse of vulnerable adults: The 2000 survey of state adult protective services, Developed by the National Association of Adult Protective Services.

[22]. Tierney, M.C., W.G. Snow, J. Charles, R. Moineddin and A. Kiss, 2007,. Neuropsychological predictors of self neglect in cognitively impaired older people who live alone. Am. J. Geriatric. Psychiatry, 15: 140-148. 